\title{
Fitness Facility Safety: How Safe are Fitness Facilities for Workers?
}

\author{
GIL FRIED \\ University of New Haven
}

Most people take for granted safety issues associated with employees. When someone is working out at a fitness facility they often are more concerned about their own personal safety or the safety of another patron. Rarely does the safety of employees come into view or consideration. With over 29,000 health clubs and fitness facilities currently in the United States (IHRSA, 2007), how safe are the several hundred thousand employees working in the industry?

More than 5.7 million workers were injured in their workplace in 2000 . An additional 5,915 workers died from traumatic injuries and over 50,000 employees died from occupational diseases (UAW-Local 2209, 2008). In 2003 there were 5,559 reported worker deaths, including 114 deaths to selfemployed workers and 61 deaths from workplace violence. However, the number of deaths per 100,000 stayed the same at 4.0 (OSHA, 2004). In 2006 work injuries resulted in 5,703 deaths in the United States, a rate of 3.9 deaths per 100,000 workers (Bureau of Labor Statistics, 2007). Besides the serious injuries, numerous less severe injuries occur including 6 million non-fatal workplace injuries that cost United States businesses more than $\$ 1.25$ billion annually (U.S. Department of Labor, 2002a). The number of non-fatal workplace injuries in 2006 averaged 4.4 injuries per 100 workers (Coy, 2007). While some jobs represent a significantly higher threat of injury, there has been a general decline in both fatal and non-fatal injuries since 1945 (Coy). With the increased cost of health care, the impact of workplace injuries in any industry can be staggering. That is why the United States Government has made a conscientious effort to reduce workplace injuries and improve workplace safety.

In order to improve the work environment for millions of employees the federal government passed the Williams-Steiger Occupational Safety and Health Act (OSHA) of 1970 (29 U.S.C. $§ 651$, et seq., 2009). OSHA also refers to the Occupational Safety and Health Administration, which is housed in the United States Department of Labor. OSHA has developed significant 
rules for monitoring the safety for 110 million workers in 7.6 million workplaces. The enforcement responsibilities are immense, but OSHA is burdened by having a limited number of inspectors. OSHA had 1,123 safety and health inspectors in 2002 and that number was reduced to 1,100 by 2004 and has stayed at that level through 2007 (OSHA , 2007). On average, OSHA can only inspect a given workplace once every 119 years (OSHA, 2004).

The 2004 OSHA budget increased to $\$ 468.1$ million (OSHA, 2004). There also are 8.39 million state and local public employees who are not covered by OSHA (UAW-Local 2209, 2002). Besides the federal coverage, 26 states operate their own OSHA programs and utilize 3,105 employees, of which 1,378 are inspectors (U.S. Department of Labor, 2002b).

OSHA has tracked numerous workplace violations over the years. In 2006 there were 38,579 workplace inspections that uncovered 83,913 violations which resulted in assessed penalties totaling over $\$ 84$ million in penalties. In addition there were more than 58,000 state OSHA inspections that uncovered 127,284 violations, resulting in the assessment of $\$ 71$ million in penalties at the state level (OSHA, 2007). OSHA is not all about penalizing employers for failing to maintain a safe workplace. Since 1971 OSHA has cut workplace fatalities by $60 \%$ (OSHA). Thus, OSHA serves a critical role in developing and enforcing regulations that have made the workplace safer for all employees.

OSHA investigations occur in all industry segments and health clubs are not immune from such investigation. Fitness facilities are identified in the Standard Industrial Code (SIC) designation as industrial code 7991 using the term "Physical Fitness Facilities" and are defined as:

Establishments primarily engaged in operating reducing and other health clubs, spas, and similar facilities featuring exercise and other active physical fitness conditioning, whether or not on a membership basis. Also included in this industry are establishments providing aerobic dance and exercise classes (U.S. Department of Labor, 2008, p. 1).

Health and fitness facilities have known about OSHA investigations and regulations for years. Various fitness industry articles have been written examining OSHA regulations/enforcement in the fitness and sport industry. For example, The American College of Sport Medicine's (ACSM's) Health/Fitness Facility Standards and Guidelines, Third Edition (2007) specifically established an "industry standard" which states that facilities must post all OSHA signs. Broadhag (2005) in an article published in Fitness Management focused on OSHA concerns associated with bloodborne 
pathogen concerns for fitness facilities. The risk of contact with bloodied patrons has motivated numerous facilities to adopt OSHA standards to protect employees and avoid violating the law.

Based on the significant impact OSHA has on workplace safety, this paper was undertaken to examine workplace safety in the fitness industry and to determine if there were any potential trends that could be uncovered by examining OSHA incident/investigation reports at fitness facilities from 1989 through 2006, using official OSHA reports.

There were 410 documented OSHA investigations of fitness facilities from 1989 through 2002, with an additional 143 investigations from 20022006. These investigations shed significant light on how OSHA investigates workplace injuries and hazards in the fitness industry. The investigations do not specify the most common problems (such as slip and fall or being struck by an object), but show what steps OSHA takes when investigating cases and whether there might be some trends and resolutions that can be developed from these investigations.

This paper will first analyze the history and purpose of OSHA and workplace injuries. Special attention will be focused on some of the specific concerns that apply to all industries and then some of the concerns that are unique to health clubs. The paper will then analyze the 553 investigated cases mentioned earlier, and then suggest some possible lessons or conclusions that can be derived from the data.

\section{HISTORY AND PURPOSE OF OSHA}

In Upton Sinclair's seminal book The Jungle (1906), the author highlighted the perils of working in the Chicago slaughterhouses at the turn of the twentieth century. Individuals who fell into the cattle chutes often were trampled and left for dead to avoid slowing down the cattle. It was not uncommon for workers to lose body parts, and workers had very little protection, if any. Similar dangerous work environments were found elsewhere including the agricultural, garment, and manufacturing industries. While it took elected officials several decades, Congress created OSHA when it passed the Williams-Steiger Occupational Safety and Health Act of 1970 (29 U.S.C. $§ 651$, et seq., 2009). The legislation was passed to "assure so far as possible every working man and woman in the nation safe and healthful working conditions and to preserve our human resources" (29 U.S.C. §651). Since 1971, OSHA has helped cut workplace injuries by more than $60 \%$, even though the United States workplace has doubled from 58 million workers in 
3.5 million worksites to 115 workers in 7.2 million worksites since 1970 (OSHA, 2004).

While workers need a safe workplace, employers are responsible for complying with OSHA regulations. Some of the duties owed by employers under the Act include: providing well-maintained tools and equipment; providing OSHA required training; posting OSHA required safety posters; keeping appropriate safety records; not discriminating against employees for filing an OSHA complaint; providing employees with access to key data concerning hazards and citations; responding to violations and survey questionnaires; and reporting all fatalities or injuries resulting in the hospitalization of three or more employees (U.S. Department of Labor, 2002b, p. 1).

Over the past several years OSHA has focused on three primary strategies including outreach and education, corporate partnerships, and "strong, fair and effective enforcement" (OSHA, 2004). Whether or not OSHA has succeeded in these efforts is not yet known. Success could be contingent on matters outside OSHA's control such as federal funding. However, through analyzing OSHA's own incident reports trends can possibly be developed concerning workplace injury investigation and regulation enforcement.

\section{FITNESS FACILITIES AND OSHA}

In 2007, there was an estimated 29,357 health clubs in the United States (IHRSA, 2007). There also were an estimated 2,617 Young Men's Christian Associations (YMCAs) (YMCA, 2007) although not all YMCAs have a health club. There also were thousands of other health clubs associated with schools, universities, and park and recreation departments.

The federal government does not have any statistics just for fitness industry employees, but has several other categories including a U.S. Department of Labor, Bureau of Labor Statistics designation "39-9031 Fitness Trainers and Aerobics Instructors," which highlighted approximately 220,000 workers in this category (U.S. Department of Labor, 2008). There were an additional 280,000 employees classified as recreation workers, 165,000 classified as coaches and scouts, and 32,000 in a miscellaneous entertainer, performer, and sport related category. If we estimate possibly 400,000 in the health and fitness club industry, based on a death rate of 4.0 per 100,000 employees (OSHA, 2004), that would equate to 16 employees dying each year from injuries occurring at health clubs. Any health club death is tragic, but if regulations can help prevent these deaths, then health club owners and managers have a legal and moral obligation to comply with such regulations. 
Through analyzing workplace injuries it is easier for a fitness facility to appreciate what risks their employees face and what issues OSHA might investigate.

\section{WORKPLACE INJURIES}

OSHA's primary focus is the investigation and prevention of workplace injuries. Every industry segment has their own unique injuries and that is why it is critical to examine general workplace injuries before specifically examining fitness facility related injuries. The most common injuries in any occupation are back-related injuries from twisting and lifting. The most frequent injuries from the 2000 survey of workplace injuries are shown in Table 1.

\section{TABLE 1}

\section{Injury Frequency Type}

\begin{tabular}{lc} 
Injury & Frequency \\
\hline Sprains & 728,202 \\
Bruises & 151,680 \\
Cuts & 141,649 \\
Fractures & 116,713 \\
Burns & 33,693 \\
Carpal Tunnel & 27,697 \\
Amputations & 9,658
\end{tabular}

("Nature of injuries," 2000).

The gender breakdown for the injuries included 1,097,104 injuries to men and 555,722 injuries to women (Rogers \& Wiatrowski, 2005). The age breakdown for these injuries are shown in table 2. 


\section{TABLE 2}

\section{Injury Frequency by Age}

\begin{tabular}{lc} 
Age & Frequency \\
\hline $14-15$ & 573 \\
$16-19$ & 54,134 \\
$20-24$ & 186,336 \\
$25-34$ & 430,922 \\
$35-44$ & 481,267 \\
$45-54$ & 325,808 \\
$55-64$ & 142,540 \\
$65-$ up & 25,335
\end{tabular}

(Nature of injuries, 2000).

These figures highlight that younger workers (under age 45) and sprains were the most frequently reported injuries. Due to the physical activity associated with fitness, employees at health clubs risk injuries such as sprains, bruises, and cuts (Career Planner.com, 2009). Furthermore, numerous workers in the fitness field are relatively young workers (Bureau of labor Statistics, 2007). Based on the types of injuries possible at health clubs and the young age of workers in the industry, Table 1 and 2 would tend to highlight the potential for significant injury claims in the fitness industry.

The most common cause of fatalities in the workplace occur in transportation incidents $(42.2 \%)$, followed by contact with objects/equipment $(16.3 \%)$, assault/violent acts $(15.3 \%)$, falls $(13.7 \%)$, exposures to substances/environment (8.5\%), and fires/explosions (3.2\%) (Fatal occupational injuries, 2003). Most injuries are not fatal and in 2005 there were 4.2 million nonfatal illnesses in the private sector workplace (Bureau of Labor Statistics, 2006). The majority of these injuries $(68 \%)$ occurred in the service industry which employs $79 \%$ of the sector workforce covered by the Bureau of Labor Statistics survey in 2005 (Bureau of Labor Statistics). The remaining $32 \%$ of the non-fatal injuries occurred in the manufacturing industries which employ $21 \%$ of the workforce. While there was no specific fitness facility category, of the potentially appropriate industry segments, the leisure and hospitality industry segments had a higher average number of nonfatal injuries, with 6.1 cases per 100 workers in the arts and entertainment segment. There were an average of 8.3 cases per 100 workers in the 
performing arts, spectator sports, and related industries. Finally, there were an average of 5.6 cases per 100 workers for the amusement, gambling, and recreation industries (Bureau of Labor Statistics, 2006). The injury frequency numbers show that fitness facilities are not a significant source of injuries compared to other industry segments.

When employees are injured on the job their exclusive remedy is the workers' compensation fund, often administered by state agencies (Fried \& Miller, 1998). While there is no national data on the average worker's compensation injury award for sport/fitness related facilities, some claims data from Washington (see Table 3) highlights the average claim payout for injuries occurring in 2002.

\section{TABLE 3}

\section{Type of Sport Workers' Claims in Washington}

\begin{tabular}{lccc} 
Risk Group & \# Claims & Total Paid & Avg. Paid \\
\hline Sport Facility Ops. & 6 & $\$ 1,757$ & $\$ 293$ \\
Baseball Teams & 53 & $\$ 96,637$ & $\$ 1,823$ \\
YMCA/YWCA & 164 & $\$ 350,429$ & $\$ 2,137$ \\
Bowling Alleys & 165 & $\$ 319,240$ & $\$ 1,935$ \\
Exercise & 174 & $\$ 422,383$ & $\$ 2,427$ \\
Golf Courses & 197 & $\$ 539,235$ & $\$ 2,737$
\end{tabular}

(Washington State Department of Labor and Industries, 2004).

These data also highlight that YMCAs and exercise facilities have a significant number of claims, in at least one state, and these injuries resulted in expenditures of over $\$ 750,000$ ( $\$ 350,429$ and $\$ 422,383)$. Thus, besides the threat of major injuries, fitness facilities need to comply with OSHA regulations to avoid major financial claims/penalties. Some employers might be motivated to make the workplace safer to reduce the threat of employee injuries. Other employers might be motivated to make the workplace safer to avoid potential penalties. Thus, OSHA serves as a means to encourage employers to maintain a safer workplace in order to avoid potential significant penalties and awards that come from injuries investigated by OSHA.

\section{OSHA INVESTIGATIONS}

OSHA investigations are categorized as complaints, investigations, referrals, and follow-ups. OSHA investigations are often initiated through a 
complaint, which is an allegation made by current/former employees or customers. Numerous people can file a complaint from a disgruntled employee to a concerned employee or patron. In contrast, an accident typically involves serious injuries resulting in death or hospitalization. Numerous minor injuries occur on a daily basis in every workplace, but these injuries are often not reported unless there is a hospitalization or a workers' compensation claim filed. Accidents are also investigated when they have occurred repeatedly at the same work site or if an incident injures multiple workers. Referrals and follow-up occur when a worksite has had previous problems that needed to be corrected or when another agency has discovered a problem and referred that problem to OSHA for investigation (Nash, 2005).

OSHA investigations for the 2002 fiscal year resulted in the following violations and penalties as presented in Table 4:

\section{TABLE 4}

Violation Types and Penalties in 2002

\begin{tabular}{lccr} 
Type & 2002 \# Violations $(\%)$ & 2002 Total Penalties & 2002 Average Penalties \\
\hline Willful & $683(0.9 \%)$ & $\$ 18,133,778$ & $\$ 26,550$ \\
Serious & $53,365(68 \%)$ & $49,107,548$ & 920 \\
Repeat & $1,992(2.5 \%)$ & $8,311,599$ & 4,172 \\
Failure to Abate & $217(0.3 \%)$ & 923,518 & 4,256 \\
Other & $22,353(28 \%)$ & $2,166,111$ & 97 \\
Unclassified & $290(0.2 \%)$ & $3,432,259$ & 11,835
\end{tabular}

(U.S. Department of Labor, 2002b).

OSHA investigations for the 2006 fiscal years resulted in the following violations and penalties as presented in Table 5:

\section{TABLE 5}

\section{Violation Types and Penalties in 2006}

\begin{tabular}{lcc} 
Type & 2006 \# Violations (\%) & 2006 Total Penalties \\
\hline Willful & $479(0.5 \%)$ & $\$ 16,009,045$ \\
Serious & $61,337(73.1)$ & $54,139,361$ \\
Repeat & $2,551(3.0)$ & $9,688,804$ \\
Failure to Abate & $288(0.3)$ & $1,044,925$ \\
Other & $19,246(23)$ & $3,098,221$ \\
Unclassified & $12(0.01)$ & $1,044,925$
\end{tabular}

(OSHA, 2007). 
The 683 willful violation cases in 2002 dropped two years later to 462 cases $(0.5 \%$ of all violations) and penalties decreased to $\$ 14,553,171$ (OSHA, 2004). The number of willful violations increased to 479 cases in 2006 , but the total penalties for willful violations increased to over $\$ 16$ million. Thus, even though the number of willful violations cases has declined by over 200 cases from 2006 to 2002 , the penalties only declined around $\$ 2$ million. Under the statute, willful violations carry a fine of $\$ 25,000$ to $\$ 70,000$ (U.S. Department of Labor, 2002b). Willful is generally defined as failing to comply with a legal regulation or acting with indifference to employee safety (OSHA, 1996). Violators can also face jail time if a death is caused by a willful violation.

Serious violations are defined as violations when the workplace hazard could cause an accident or illness that would likely result in death or serious physical harm. From 2002 to 2006 the number of serious violations increased from 53,365 to 61,337 . Serious violations can result in a fine of $\$ 7,000$ per violation (Barnett, 2001).

If an employer has been cited for any violations, they can correct the condition by the assigned date and/or request an Informal Conference with the OSHA Area Director to discuss the violations/abatement dates, pay the fine, or appeal the violation (OSHA, 1996). Many employers try to correct or try to reduce the fines through a hearing.

\section{OSHA WORKPLACE CONCERNS}

When OSHA starts an investigation, one of the first issues they will examine are policies and procedures to insure a safe workplace. For example, one of the key facility concerns is the ability to exit the workplace if an emergency shall arise such as a fire. OSHA regulations cover various emergency exiting concerns such as exit routes, emergency action plans, and fire prevention plans. Every fitness facility needs to have at least one fire extinguisher. Any workplace that has one or more fire extinguishers, and which would need to be evacuated during an emergency, needs to have an emergency action plan (EAP) (29 C.F.R. 1910.38, 2009). The EAP focuses on how to get workers out of the workplace as soon as possible to a safe area whether it is inside or outside the workplace (OSHA, 2004). A survey of college recreational facility managers found that $92.5 \%$ had an emergency action plan (EAP), however only $72.3 \%$ of the facilities actually practiced their EAP. The EAPs were primarily taught to employees at orientation $(41.2 \%)$ and $38.2 \%$ of respondents taught employees the EAP on a semiannual 
basis (Connaughton, et al., 2002). In fact, over $70 \%$ of OSHA fines are prompted not by injuries, but by an employer failing to have a written OSHA Safety Plan (IHRSA, 2003).

Safety planning can also be seen in OSHA's requirement for personal protective equipment (PPE). PPE can include protective equipment that can protect eyes, head, feet, arms, hands, and hearing protection. Hearing PPE can range from single use earplugs to preformed/molded earplugs, and even earmuffs. Having PPE equipment is not enough to meet OSHA mandates. Employees need to be trained in workplace hazards that can impact hearing, how the equipment can protect them, what limitations the equipment has, when they have to wear the equipment, how to properly use the equipment, how to use equipment while using other safety equipment, and how to care for the equipment (U.S. Department of Labor, 1997). All these elements require planning since every fitness facility needs to train its employees on how to use the equipment, and needs to have the equipment available. Due to the loud music played at fitness facilities (for example during aerobics class) PPEs can be a critical concern as discussed later in this paper.

One of the most frequently seen OSHA violations entails improper employee training or a lack of training whatsoever (Kenworthy, 2002). For example, if an employee failed to carry out their responsibilities in a safe manner, the excuse that is often raised by the employee is that they did not know or were never trained in proper procedures. The most effective means to address this concern is to have written rules, policies, and/or procedures directed at the hazard in question (Kenworthy). The next key is to show that the rules or policies were effectively communicated to the employees. OSHA requires employers to instruct their employees in the recognition and avoidance of hazards specific to their work site, hazards that a reasonably prudent employer would have known about. Thus, even open and obvious risks still need to be analyzed and specific strategies need to be developed to educate employees on how to avoid the obvious hazardous condition. In one case an OSHA violation for failing to provide appropriate training was upheld where the employees were not trained in the proper way to cross "on foot" a multi-lane freeway (W.G. Fairfield Company v. Occupational Safety \& Health Review Commission, 2002, p. 500). While it could be assumed that all employees would know that crossing a freeway is dangerous and caution needs to be taken, an employer has to go one step further and provide education and training to all employees who might reasonably have to cross a freeway on foot.

The first question that OSHA will ask is whether there were workplace rules directed at the hazard in question (Kenworthy, 2002). The second 
question that will be asked is whether the employer can establish that they had a safety program in place that adequately communicated the hazard to employees and trained them to avoid the hazard (Kenworthy, 2002). If an employer can show that the employees were well trained, knowledgeable, and experienced in executing the safety rules, the employer should have a strong argument when OSHA investigates an injury. That is why fitness facilities need to understand and follow all applicable OSHA regulations.

Several specific OSHA regulations have a prominent and direct impact on the thousands of fitness facilities and employees. For example, OSHA issued a standard entitled Occupational Exposure to Blood Borne Pathogens (29 C.F.R. 1910.1030, 2009). This standard applies to any employer whose employees might reasonably anticipate exposure to blood or other potentially infectious bodily fluids while performing their job, such as those working in the sport industries (Connaughton, et al., 2002). The standard was designed to help reduce exposure to potentially infectious materials by having the employer implement plans, develop educational materials and document incidents in an appropriate manner. These requirements are set forth in an Exposure Control Plan (ECP) and since fitness facilities can reasonably anticipate having a blood spill, they would need to comply with an ECP. This could entail providing appropriate warning labels, and providing free education seminars for employees. If an employer does not have an ECP in place, they are in violation of OSHA standards (Connaughton, et al.).

One of the most commonly overlooked hazards present in fitness facilities involves sound related hazards. The maximum level at which music can be listened to safely for 30 minutes ( 105 decibels) is regularly violated by aerobic instructors (Brodsky, 2002). In one study of 90 clubs, $80 \%$ of the clubs violated the OSHA sound safety standards by playing the music over 105 decibels during aerobic classes (Brodsky). In fact, $60 \%$ of the health clubs had either the music and/or the instructor's microphone exceeding 110 decibels (dBA) during a one-hour class. OSHA standards highlight that an employee (let alone a customer) should not be exposed to that sound level for more than 15 minutes (29 C.F.R. 1910.95, 2009). In another study, a San Francisco dance club had music blasting at $105 \mathrm{dBA}$, which is louder than a sandblaster (Walsh, 2001). According to the National Institute for Occupational Safety and Health (NIOSH), someone should limit their time in that environment to 4 minutes and 43 seconds (Walsh, 2001). In fact NIOSH recommends that any employee exposed to sound over $100 \mathrm{dBA}$ wear both earplugs and earmuffs (PPE). OSHA regulations require anyone working in sound levels over 85 $\mathrm{dBA}$ to wear ear protection, given regular hearing exams, and receive employer-sponsored hearing loss education programs (29 C.F.R. 1910.96). 
In response to sound concerns in the workplace, OSHA has developed new standards requiring employers to institute a hearing conservation program with annual audiometric testing whenever the sound level in the workplace exceeds 85dBA. Employers are also required to complete a hearing loss column when recording work-related injuries under the OSHA record keeping standards (Safety/OSHA Update, 2004). Violating noise related rules can result in both an OSHA investigation and penalties. Failing to institute a noise conservation program, utilize engineering controls to reduce noise exposure, and conduct audiometric testing cost one Alabama employer $\$ 55,150$ when the workplace noise level was as high as 100dBA (Safety/OSHA Update).

Similar to other industries, fitness facilities could be safer for employees if appropriate safety training is provided. Even though health clubs are not as dangerous as construction or manufacturing industries, OSHA started making efforts in 2003 to reach health clubs, golf courses, and related recreational facilities that often employ young workers and have transient workforces. In 2003 OSHA entered into an alliance with the Club Managers Association of America (CMAA) to focus on hazard communication, respiratory protection, and record keeping (U.S. Department of Labor, 2003). CMAA's 6,000 member managed clubs employ over 300,000 employees across the U.S. (U.S. Department of Labor). The alliance is attempting to develop training courses, educational programs, and "tool box talks" in both English and Spanish.

To be proactive, the International Health and Racquet Sportsclub Association (IHRSA) established a relationship with a supplier to provide OSHA safety plans and posters to its members (IHRSA, 2003). Thus, while dangers exist, the industry is taking action to reduce injuries.

\section{OSHA RESEARCH PROCESS AND RESULTS}

OSHA inspection reports are available on the OSHA web page (www.osha.gov) and are public records. Through entering in the SIC code 7991 as the search criteria, the researcher was able to obtain a list of 410 cases dating back to 1989 and ending in 2001 . While there can be sport, fitness, and health facilities listed under various SIC codes, 7991 is the most frequently cited code for fitness facilities. There were 410 OSHA reports filed between 1989 and 2002. The data was synthesized into an SPSS format for analysis. Of the 410 inspection reports, 10 were filed against government owned fitness facilities (2.4\% of all reports), 30 against YMCAs (7.3\%), and 370 involved private facilities $(90.2 \%)$. The primary years analyzed were between 1990 and 2001, since only three reports were entered into the database in 1989 and four 
were entered in 2002 when the data was gathered. These reports were developed in response to accidents, planned investigations, or complaints.

Not all investigations resulted in negative findings. Similar to being investigated for a crime, just being investigated does not mean that someone is guilty. Even if an investigation showed a facility violated OSHA regulations the investigator might not have imposed a penalty or might not have documented the violation. Nonetheless, $42 \%$ of the investigations led to some penalty being assessed as discussed below.

A subsequent sampling was taken in 2007 which analyzed the 143 reports filed between 2002 and 2006 to see if the trends identified in the first survey continued. The results from 1990 through 2001 are called the first study and the results from 2002-2006 are referred to as the second study.

While a health club might not appear to be that dangerous, two of the cases highlighted in this study involved deaths. This is far shy of the expected death (16) using the rate of 4.0 deaths per 100,000 employees. The fatalities included a private facility in New Jersey that was cited for two serious and three "other" violations resulting in initial penalties of $\$ 3,750$. The penalties were in response to the electrocution of an employee who started an electric motor at a workbench, and due to improperly spliced and un-insulated wiring the employee was electrocuted and died. The deceased was a 62 year-old male and the accident occurred in May, 1991. The case took five months to complete and the final penalty was reduced to $\$ 2,750$.

The other fatality in this study also occurred in 1991. The incident occurred in a private club in Tulsa, Oklahoma and no penalties were accessed. The incident was not really a facility related policy or defect case, but rather a personal accident. A 39-year-old employee was suffering back problems and was taking medication that made her a bit dizzy. She decided to go to the Whirlpool and approximately 30-45 minutes later she was found lying on her side in the whirlpool. The case was opened and closed within one month.

\section{Average Award}

While the threat of penalty might serve to encourage employers to comply with OSHA regulations, almost $58 \%$ of the studied cases involved no initial penalty. Only 174 cases involving an initial penalty, which represented $42.4 \%$ of all cases investigated. The penalties were accessed for a wide variety of violations ranging from the failure to post required signs, to unsafe work conditions that contributed to the death of an employee. The minimum penalty was $\$ 60$ and the highest was $\$ 32,400$. The mean penalty was $\$ 2,504$. In the second study (2002-2006 investigations) the lowest minimum penalty 
was $\$ 50$ and the highest penalty was $\$ 37,825$. It should be specifically noted that initial penalties are often reduced through negotiations. Thus, most cases had an "initial penalty" and then a "current penalty," which could have resulted from abatement activity, appealing a fine, or other activities that helped reduce or eliminate the "initial penalty." The minimum current penalty on the cases in the first study was $\$ 60$ and the maximum was $\$ 12,960$. The mean current penalty for the study was $\$ 1,529$. Thus, the initial penalty was reduced on average $\$ 975$ to generate the current penalty.

Table 6 highlights the number of cases in the two studies that resulted in initial penalties. The number of cases resulting in penalties was fairly consistent except for a spike in 1992 and 1993. However, the second study showed a significant increase in the number of cases with penalties. The average award has fluctuated significantly ranging from a low of $\$ 1,149$ in 1990 to high of $\$ 6,183$ in 1991 . The next highest average was $\$ 4,128$ in 2001 . The 1991 average is skewed by two large penalties including cases with $\$ 32,400$ and $\$ 17,000$ in penalties.

\section{TABLE 6}

Average and Total Penalties in OSHA Fitness Investigations

\begin{tabular}{lccc} 
Year & \# of cases & Average Penalty & Total Penalties \\
\hline 1990 & 8 & $\$ 1,149$ & $\$ 9,190$ \\
1991 & 11 & 6,183 & 68,015 \\
1992 & 13 & 3,720 & 48,370 \\
1993 & 21 & 2,622 & 55,059 \\
1994 & 22 & 1,826 & 40,170 \\
1995 & 17 & 2,227 & 37,858 \\
1996 & 13 & 1,324 & 17,220 \\
1997 & 11 & 1,247 & 13,725 \\
1998 & 19 & 1,718 & 32,650 \\
1999 & 7 & 2,074 & 14,520 \\
2000 & 11 & 2,254 & 24,800 \\
2001 & 15 & 4,128 & 61,920 \\
2002 & 26 & 2,737 & $71,160 \mathrm{a}$ \\
2003 & 38 & 1,205 & 45,785 \\
2004 & 24 & 3,003 & 72,070 \\
2005 & 32 & 1,944 & 62,195 \\
2006 & 23 & 2,357 & 54,205 \\
\hline
\end{tabular}

a - Represents findings from the second study. 
The most frequent penalty amount from $1990-2001$ was $\$ 750$, which was assessed nine times. The next most frequent amount was a $\$ 300$ penalty assessed seven times. The combined 174 cases in the first study produced initial penalties totaling $\$ 435,792$. By dividing the total penalties of $\$ 435,792$ by the 12 years analyzed produced an average total yearly penalty of $\$ 36,964$.

\section{Penalty Based on Ownership Structure}

Ownership structure for the club was determined in part based on the facility name or other disclosed information. Some clubs were popular chain names while others specially mentioned "YMCA" or "city of" in the incident report. The initial penalties vary based on a variety of factors, but the facility ownership structure appears to have some impact. For example, in terms of the greatest grouping of initial penalties (penalties between $\$ 280-\$ 460$ from 1990-2001), there were 7 YMCAs (35\% of all YMCA cases with penalties) versus 18 private facilities $(11.9 \%)$. Thus a YMCA was three times more likely to receive a lower initial penalty than a private facility. In contrast, while one YMCA received a penalty over $\$ 10,000$, seven private clubs received penalties ranging from $\$ 10,800$ to $\$ 32,400$.

This analysis should be tempered by the fact that no YMCA was fined less than $\$ 270$, only one government facility faced this lower level penalty, and 24 private facilities had fines between $\$ 60$ and $\$ 270$. This represents a relatively large percent of private penalty cases $(15.9 \%)$. Thus, a significant number of private clubs were able to escape without a larger penalty. This number could be misleading. It could mean, for example, that YMCAs were not fined for minor violations and only faced fines for more serious violations. Thus, based on initial penalties, there does not appear to be any discernable or provable bias.

The mean initial penalty for government facilities in the first study (19902001 ) was $\$ 1,620$ and ranged from $\$ 185$ to $\$ 2,800$. YMCAs had a mean initial penalty of $\$ 2,257$ and ranged from $\$ 280$ to $\$ 12,150$. Private facilities had a mean initial penalty of $\$ 2,555$ and ranged from $\$ 60$ to $\$ 32,400$. As previously highlighted, penalties are regularly reduced and finalized as "current penalties." The mean initial and current penalties based on ownership structure are highlighted in Table 7 . Current penalties are more flexible and judges/administrators can have more latitude compared with mandatory initial penalties set by statute. To avoid the cost of litigation, a judge/administrator can reduce the initial penalty assessed an employer for violating regulations. This process is similar to how a defendant in a criminal case can plea bargain to reduce their potential fines or jail/prison time. 


\section{TABLE 7}

\section{Penalty Differential based on Ownership Structure}

\begin{tabular}{lcccc} 
Facility type & Mean Initial Penalty & Mean Current Penalty & Difference & Perct. Diff. \\
\hline Government & $\$ 1,620$ & $\$ 1,053$ & $\$ 567$ & $-35 \%$ \\
Private & $\$ 2,555$ & $\$ 1,610$ & $\$ 945$ & $-37 \%$ \\
YMCA & $\$ 2,257$ & $\$ 979$ & $\$ 1,278$ & $-57 \%$
\end{tabular}

This chart highlights that YMCAs were given the greatest reduction in penalties. It is not known whether ownership structure influences what penalties are ultimately accessed against a facility, but the difference between private fitness facilities and YMCAs is $20 \%$. This information may indicate that OSHA administrators and enforcers are more willing to cut a deal with YMCAs rather than government or private facilities. This could be due to personal bias rather than a set agenda to punish others. However, potential bias can be seen in one primary region, the west coast.

\section{Comparison of State Awards}

Only three states had a double-digit number of cases with initial penalties. California had 64 cases involving initial penalties and represented $52.9 \%$ of all California cases. Some of the more prominent states with more than five investigations during the first study (1990-2001) and the ownership structure that was investigated is highlighted in Table 8. 
TABLE 8

Ownership Structure in the Most Frequent States Analyzed

\begin{tabular}{lcccc} 
State & Government & Private & YMCA & Total \\
\hline AK & 0 & 5 & 0 & 5 \\
AZ & 3 & 11 & 0 & 14 \\
CA & 4 & 113 & 4 & 121 \\
ID & 0 & 6 & 0 & 6 \\
IL & 0 & 4 & 6 & 10 \\
MD & 0 & 3 & 3 & 6 \\
MN & 1 & 11 & 0 & 12 \\
NC & 0 & 16 & 0 & 16 \\
NJ & 0 & 9 & 1 & 10 \\
NV & 0 & 8 & 0 & 8 \\
NY & 2 & 13 & 0 & 15 \\
OR & 0 & 15 & 1 & 16 \\
TX & 0 & 18 & 0 & 18 \\
VA & 0 & 7 & 1 & 8 \\
WA & 0 & 64 & 0 & 64 \\
Total & 10 & 303 & 16 & 329 \\
\hline
\end{tabular}

In the initial survey there were 10 investigations that occurred in government facilities, 30 in YMCAs, and 370 in private clubs. While the following states only had investigation of private clubs: Arkansas, Conecticut, Idaho, North Carolina, Nevada, South Carolina, Tennessee, Texas, and Washington. The survey results for incidents between 2002-2006 included nine government facilities, 19 YMCAs, and 115 private clubs. Of these cases, California led the nation again with 39 private facilities being investigated, one government facility, and two YMCAs. Washington had investigations at six private clubs, and Oregon had one YMCA and 10 private facility investigations.

California and Washington had the highest number of cases, which represented the greatest opportunity for trying to develop potential trends. There were 64 inspections in California (1990-2001) that resulted in penalties. The next most frequently occurring state in terms of penalties was Washington with 13 cases. When analyzing smaller penalties from $\$ 60-\$ 330$, California had 19 cases $(29.7 \%$ of all California cases), with an average of $\$ 174.57$ for these cases. Thus, almost $30 \%$ of the fined facilities in California were fined less than $\$ 350$ for their violations. In Washington, five of the $13(38 \%)$ cases 
were under $\$ 330$ with the average for these five cases being $\$ 214$. California had a mean $\$ 1,257$ initial penalty, which ranged from $\$ 75$ to $\$ 7,750$. Washington had a mean of $\$ 1,931$ and a range from $\$ 90$ to $\$ 13,940$.

Just because a state might have a large number of investigations does not mean that the penalties would be greater than other states. For larger initial penalty cases (over $\$ 3,750$ in penalties) California had only four cases $(6.25 \%$ of all California cases), and these four cases averaged $\$ 6,531$. This shows that while California had a large number of inspections the majority of those initial penalties resulted in relatively small fines. Ohio, with only three cases, had the highest average penalty with a $\$ 24,700$ average. However, this average is significantly skewed since two of the three cases included the two highest fines in the study $(\$ 17,000$ and $\$ 32,400)$. Similarly, New York and Minnesota had high comparative averages. Eight of New York's 10 cases had penalties over $\$ 3,750$, with the average being $\$ 8,643$ for those eight cases; the total average for all of New York's 10 cases was \$7,262. Three of Minnesota's seven $(42.8 \%$ ) cases had awards over $\$ 3,750$, with their average being $\$ 7,502$. These results showed that California does not have the highest average penalties even though California had the highest number of investigations. The difference between the number of investigations in any given state and the penalties imposed in that state can be a function of the desire by investigators to focus on less frequent, serious incidents, or more frequent minor incidents. Thus, OSHA investigators can help set the trend for the number of investigations or the type of investigations that will be conducted.

\section{Frequency of Investigations}

The years with the most number of investigations were 1993 with 47 and 1991 with 42 . California, with the greatest number of cases ranged from three investigations in 1990 to 16 in 1993 . The number of investigations was well dispersed across the study period. Washington, in contrast, had a concentration of cases in just two years with 12 investigations in 1993 and 11 in 1997. The abundance of cases in California, Oregon, and Washington tends to promote the fact that there might be a west coast OSHA office that is more aggressive then other offices. This assertion is based on the fact that 201 of the 410 OSHA investigations occurred in those three states.

The International Health, Racquet and Sportsclub Association (IHRSA) published a study in 2007 highlighting yellow page listings throughout the United States of health clubs and fitness facilities under the SIC-7991 designation. The findings highlighted that $66 \%$ of the 29,357 health clubs in the United States are commercial while $34 \%$ were non-profit (IHRSA, 2007). 
Under regional facility analysis, there were 6,184 clubs in the northeast, 10,067 clubs in the south, 6,570 clubs in the north central, and 6,572 clubs in the west. The number of clubs in the west has grown significantly over the past 10 years. For example, there were 1,421 clubs in California in 1996 and that number grew to 3,203 clubs by 2007 . Similarly, Oregon grew from 207 clubs to 418 clubs and Washington grew from 262 to 680 clubs during the same time frame (IHRSA, 2007). Using these figures, there were 4,301 clubs in Oregon, Washington, and California in 2007. Based on 4,301 clubs, in 2007 the three west coast states had approximately $14.65 \%$ of the total number of health clubs in the United States. A conservative estimate for what percentage of west coast clubs should have had investigations could be 10 $20 \%$ of the total number of cases. The OSHA reports analyzed showed that over $49 \%$ of the cases originated from these three states. Thus, a disproportionate number of cases are based in California, Oregon, and Washington. There is no statistical rationale for why such a large percentage of investigations originated in those states. This represents an intriguing future research focus that would require direct interviews with OSHA inspectors.

\section{Time to Investigate}

The length of time required to complete an investigation is also a major factor in analyzing how quickly or thoroughly OSHA investigates fitness facilities. The investigation length can also be a stressful issue for those dealing with an OSHA investigation since it might require a significant time commitment to respond to investigators and answer questions. In California, $34(28.5 \%)$ of the cases $(1990-2001)$ were resolved in one month or less. In addition, $86(72.2 \%)$ of California cases were concluded within seven months. In contrast, $25 \%$ of the Oregon cases took between 10-20 months to conclude the investigation. Washington appeared to be more diverse with cases being investigated from one month to over 56 months. Four of Washington's 64 cases took more than 35 months to conclude the investigations. Washington was the state with the longest average investigations, with $57 \%$ of the cases taking more than 35 months to conclude. Texas appeared to be the most efficient or expedient state with 17 of the state's 18 investigations $(94.4 \%)$ concluded within four months. The mean length of time required to complete an investigation was 5.89 months. When analyzing all the states together, 142 cases $(34.9 \%)$ were resolved in less than one month and $323(79.4 \%)$ of the cases were resolved in less than 8 months. This shows that in general investigations are resolved fairly quickly. 
The average government owned facility cases ( 10 cases) took 2.6 months to complete the investigation. The 30 YMCA cases took on average 4.73 months to complete. Private clubs, with 367 cases, averaged just over 6 months with a standard error of .44 . Based on the significant additional time required to investigate private clubs, it is important to examine why the average private club investigation took twice as long as the average government facility investigation. The data did not highlight why some investigations took longer than others. Thus, there is no identifiable reason for the longer investigation. Possible reasons for longer investigations include more detailed/critical analysis, attempts to delay the investigation, not providing accurate charges, providing inaccurate information to investigators, and other possible delays.

\section{Violations}

OSHA citations need to describe the alleged violation with particularity, reference which standard(s) was violated, establish a reasonable time frame to fix the violation, and specify the exact monetary sanctions (Fried \& Miller, 1998). Violations can be classified as willful, non-willful, serious, nonserious, repeat, first time, and failure to abate. The beginning penalty is $\$ 7,000$ for each serious violation. Willful violations can increase a nonserious violation penalty up to five times, and if a serious injury results, the penalty can be increased ten fold to $\$ 70,000$ (Fried \& Miller). Thus, workplaces try to comply with an OSHA investigation that could lead to more serious penalties. One of the benefits of quickly complying with OSHA demands is that the penalties are often reduced. However, if a workplace has not taken safety seriously, and/or has had numerous OSHA violations that have not been fixed, then the penalties can be used to punish the employer.

Of the 410 inspections undertaken during the first analyzed period, OSHA inspectors reported 270 (65.9\% of the 410 reports) violations and $119(29 \%)$ serious violations. Serious violations are not as frequently noted compared with ordinary violations, and $58.8 \%$ (70 cases) of all cases reporting serious violations had only one or two serious violations. The greatest number of serious violations was 14 in one case. Table 9 shows that $88.9 \%$ of all cases involving violations had six or fewer violations. 


\section{TABLE 9}

\section{Frequency of OSHA Violations}

\begin{tabular}{lcc} 
Number of Violations & Frequency & Percent \\
\hline 1 & 56 & $13.7 \%$ \\
2 & 67 & 16.3 \\
3 & 42 & 10.2 \\
4 & 34 & 8.3 \\
5 & 29 & 7.1 \\
6 & 12 & 2.9
\end{tabular}

In addition to these cases, 30 cases had more than six violations with the highest number of violations in any one case being 17 violations.

The number of violations can also be examined by the state in which they were reported. Twelve states had some type of violation reported in every OSHA investigation conducted. As highlighted below, seven of these 12 states had serious violations in each case. California led the states with 82 cases involving violations. This represents $67.8 \%$ of all California investigations. The top five states with violations are listed in Table 10.

\section{TABLE 10}

\section{States with the Highest Number of Violations}

$\underline{\text { State }}$ Cases with violations Perct. of all cases Mean \# of violations

\begin{tabular}{llll}
\hline CA & 82 & $67.8 \%$ & 3.04 \\
WA & 41 & 64.1 & 3.29 \\
NY & 11 & 73.3 & 6.36 \\
OR & 11 & 68.8 & 4.18 \\
NC & 10 & 62.5 & 4.10
\end{tabular}

These numbers show that there was a great likelihood (over $60 \%$ ) that when an investigation was conducted there would be violations found. The mean number of violations in California was 3.04 with the range being from one to 13 violations identified in one case. New York had a higher average than the other states with a large number of reported violations. The New York range was from two to 12 violations with a mean of 6.36 violations. The three cases from Ohio averaged 8.67 violations with each case having between 7 to 10 violations. 
Serious violations are a major concern due to the potential for death or serious bodily injuries. A serious violation is defined as "when a workplace hazard could cause an accident or illness that would most likely result in death or serious physical harm ("Federal Employer," 2002). Of the 121 cases in Californa, 22 cases $(18.2 \%)$ resulted in serious violations being accessed against the employer. This percent held constant with some of the other key states such as Washington and Oregon where $18.8 \%$ of all violations in both states were categorized as serious. Other states had a high percentage of serious violations. This could mean that in these states the investigators emphasized serious violations over minor infractions. Table 11 highlights the states with the highest number of serious violations as a percentage of all violations.

\section{TABLE 11}

\section{States with the Highest Number of Serious Violations}

\begin{tabular}{lcc} 
State & Numb of Serious Violations & Percent of all violations \\
\hline UT & 2 & 100 \\
MA & 5 & 83 \\
IL & 8 & 80 \\
VA & 6 & 75 \\
NJ & 7 & 70 \\
NY & 10 & 67
\end{tabular}

The average number of serious violations in California cases ( 22 cases) was 1.91 , with a minimum of one and a maximum of five serious violations. In Washington the 12 cases with serious violations had a range of one to 14 violations, with an average of 2.75 . The average was much higher in New Jersey where the average was 3.14 serious violations, with a range of one to five serious violations. The mean average of serious violations was higher in New York and Ohio. New York had a mean of 4.60 serious violations with a range of two to seven violations reported. Ohio had a mean of 6.0 with a range of five to seven serious violations in three cases. Any serious violation should be considered an important issue for an employer to address and all fitness facilities should be concerned with such violations. Besides the risk of injury to employees and patrons, an unsafe work environment with serious violations, or potentially serious violations, will have a harder time attracting and retaining employees, and probably patrons as well. 


\section{Health vs. Safety}

Investigating accidents is only part of the OSHA story. Not all investigations and fines relate to accidents. OSHA classifies their investigations in two categories-health and safety (29 C.F.R. 1926.20, 2009). Safety is normally related to an accident, but can also include the violation of safety rules from a surprise investigation that did not occur as the result of an accident.

Investigations undertaken for health concerns can refer to violating rules that could possibly lead to injuries or an unsafe workplace. Government run fitness facilities had five health and five safety issues highlighted in the 10 cases investigated. YMCAs had 21 health $(70 \%)$ and nine safety issues. Private facilities had 159 health related investigation (43\%) and 211 safety related investigation $(57 \%)$. Thus, the survey showed that private clubs either had more safety concerns than YMCAs (and YMCAs had more health concerns) or that the private clubs were investigated more frequently for safety concerns and YMCAs were investigated more frequently for health concerns.

The 2002-2006 survey highlighted 68 health violations and 75 safety violations. Of the 68 health violations, 52 involved private facilities $(76 \%), 14$ were YMCAs $(20 \%)$, and two $(3 \%)$ were government facilities. The safety violations were more frequently sited against private owners with $63(84 \%)$ of the cases while YMCAs represented only five $(6.6 \%)$ cases and government facilities represented seven $(9.33 \%)$. Thus, there appears to be a trend for private facilities to face safety violations, which traditionally carry higher penalties than health violations.

\section{Reason for Investigation}

Why is there a possible difference in investigations between the various types of facility owners/operators? This can possibly be due to why an investigation was in fact undertaken. Inspections were reported based on accidents, complaints, planned, referrals, follow-ups, and unprogrammed. Accident inspections are straight forward as OSHA regulations require accident inspection for serious accidents (U.S. Department of Labor, 2005). However, the other categories are either based on discretion exercised by OSHA, or investigating complaints raised by employees, customers, and other aggrieved/concerned individuals. Of the 410 analyzed inspections from 19892002 , nine were unprogrammed, 13 were based on accidents, 26 were followups on prior inspections, 73 were planned, and 255 were based on complaints. The types of investigations and the numbers are highlighted in Table 12. 
TABLE 12

Most Frequently Identified Inspections

Inspection Type

Frequency

1990-2001

(2002-2006)

Percent

1990-2001

(2002-2006)

Accident

Complaint

Follow up

Planned

Referral

Unprog Rel

$13(7)$
$255(90)$
$26(4)$
$73(23)$
$34(18)$
$9(2)$

On a national basis (based on 39,167 total inspections), $23.4 \%$ of inspections in 2004 were based on complaints or accidents, $55.1 \%$ were high hazard targeted investigations (mining, construction and other hazardous industries), and a combined $21.5 \%$ were referrals, planned, follow-ups, and unprogrammed (OSHA, 2004). In this analysis, complaints represented the greatest number of reasons for inspections, with 229 complaints filed against private facilities (70\% of all private inspections), and 21 at YMCAs (61\%). There were no referral-based investigations of government owned facilities, but six YMCAs and 28 private facilities had a follow-up referral investigation. The results showed that 11 of the 13 investigated accidents occurred at private facilities between 1999-2001. In the second study, the number of complaints at private facilities decreased to $62 \%$ ( 72 of 116 private cases), and represented $80 \%$ (72 of 90 ) of all complaints. Approximately $74 \%$ (14 of 19) of all cases against a YMCA were complaints which meant that from 2002-2006 there was only one planned inspection, one accident investigation, and three referral investigations at YMCAs.

The various complaint totals show that OSHA is more inclined to investigate a fitness facility, no matter who the owner is, based on a complaint. This means that facilities need to try and make employees and patrons feel like the facility is safe to hopefully avoid a complaint. If employees feel a workplace poses a hazard, they might file a complaint with OSHA if they feel management is not taking steps to abate a hazard. Thus, by proactively responding to workplace hazards a fitness facility could reduce employee injuries, but also can create an environment where employees are less likely to file a complaint. 
In one study, OSHA investigations in the 1990s showed significant "nonissues" with OSHA investigations. The study highlighted that $30 \%$ of all OSHA and state complaint investigations uncovered no violations and over $50 \%$ of the remaining complaint investigations found no willful or serious violations (OSHA, 1997). The study further highlighted that from 1989-1993 141,678 inspections, or $19 \%$ of all inspections performed, were in response to employee complaints. Of these complaint based investigations, $81,505(58 \%)$ failed to uncover any willful, repeat or serious violations, and 43,523 (31\%) failed to uncover any violations (OSHA).

It should be noted that disgruntled employees can file complaints even if a workplace is in compliance with all OSHA regulations. Another potential reason for so many complaints being investigated involves union related disputes. If a workplace is trying to unionize, employees can try to impact the workplace by filing numerous complaints. The study author went on to analyze workplaces with strong union management relationships and industries with significant workplace union/management strife and concluded that workplaces with strong union management relations had much fewer complaints than strife impacted workplaces (OSHA, 1997). The disparity could be based on a venomous workplace, but also could be based on a strong work environment where management and employees work together to make the workplace safer, which could result in fewer complaints.

The most surprising numbers are for follow-up and planned investigations. There was one government owned facility, no YMCAs, and 25 private facilities that faced follow-up investigations. The 25 private facilities subject to follow-up and planned investigations represent $14.8 \%$ of all private club investigations.

Based on approximate $15 \%$ follow-up or planned rate, it could be argued that there should have been an equal percentage of follow-up cases with YMCAs. Based on $15 \%$ of all the YMCA investigation there should have been at least four YMCA investigations involving either a follow-up or planned investigation. No YMCA investigations resulted in a follow-up during the first studied period. There were only 4 follow up cases during the second study and all were at private facilities. This disparity could be based on personal bias from OSHA investigators or from private fitness facilities not being as forthcoming to correct problems. Likewise, the disparity could be attributable to YMCA complying with the complaints or prior investigations. There is no proof as to why investigators might follow-up or schedule planned investigation, especially with fitness facilities, which are traditionally less prone to serious injuries compared to coal mining, construction, and similar industries (Bureau of Labor Statistics, 2006). Even the Department of Labor 
highlights that, "[t]here are currently no specific standards for accident investigations." (U.S Department of Labor, 2009). However, after this study was concluded, the U.S. Department of Labor issued a new 329 page Field Operations Manual (FOM) on March 26, 2009 (U.S. Department of Labor, 2009). The FOM highlighted hat investigation priority would first focus on imminent danger and then second on fatalities and catastrophes. The FOM also highlighted that follow-up investigations take priority over all programmed inspections.

The story is not the same with planned investigations. Three government owned facilities were documented as planned inspections, no YMCAs were planned, and 70 private facilities underwent planned inspections. Based on a percentage of total inspections, $18.9 \%$ of all private facility inspections were planned. Using this percentage it would be assumed that $5.6(18.9 \%)$ of the 30 YMCA inspections would have been planned. However, since no YMCA had planned inspections, there should be some explanation for this discrepancy and for the fact that no YMCA received a planned inspection since 1989. The $2002-2006$ survey showed that the same trend continues as $95.6 \%$ of all planned inspections were against private and government facilities.

\section{Scope of Inspection}

Every OSHA investigation can be a simple review of records or a complex review of an entire company. Table 13 highlights the scope that the OSHA investigators were examining at the fitness facilities.

\section{TABLE 13}

\section{Scope and Frequency of OSHA Investigations}

\begin{tabular}{lcc} 
Scope of Inspection & Frequency & Percent \\
\hline Complete & 140 & $34.1 \%$ \\
No inspection & 18 & 4.4 \\
Partial & 251 & 61.2 \\
Records only & 1 & .2
\end{tabular}

OSHA records allow for recording four types of inspections: complete, no inspection, partial, and records only inspections. These terms are relatively straightforward. Government owned facilities had five complete and five partial inspections. YMCAs had one complete and 29 partial inspections. Private facilities had 134 complete inspections $(36.2 \%$ of all private facility inspections), 217 partial inspections, 18 no-inspections, and one records only 
inspection. In contrast, $96.66 \%$ of the YMCA inspections were partial investigations. This means that a private facility had a much greater chance of facing a complete inspection, while a YMCA faced only limited inspections. Thus, if a private facility faced the threat of a complaint, that complaint could possibly lead to a complete inspection, and the uncovering of additional violations. In contrast, if a complaint was lodged against a YMCA, the YMCA would almost always only face a minimal investigation. This hypothesis would quickly be destroyed if there was a serious incident involving death where OSHA would undertake a thorough investigation regardless of who owned the facility. By having only a partial investigation, OSHA might not be able to identify and correct other problems that could have been uncovered through a complete inspection.

It also needs to be noted that a complete inspection results in more significant workplace interruption and costs. A partial inspection might involve visiting just an accident scene. A complete inspection could entail visiting an accident scene, visiting the rest of the facility, and demanding records. Such a complete inspection could be very costly with a facility having to close down, workers being interviewed, records being examined and copied, potential negative publicity, and other related costs.

The study results highlighted that a majority of OSHA fitness club investigations resulted in no initial penalty. Initial penalties ranged from $\$ 50$ to $\$ 37,825$. The average and mean current penalties varied based on the number of investigations each year and the severity of the hazards found during the investigation. Government, YMCA, and Privately owned fitness facilities were examined to see if there existed a major discrepancy between penalties and ownership structure. Initial penalties were lowest for government owned fitness facilities and higher for YMCA and privately owned facilities. However, initial penalties were reduced the greatest amount for YMCA and the difference was a 20 percent reduction. There is no identifiable reason for this discrepancy and the analyzed investigations did not highlight investigators or judges/administrators who might have been involved in the process. Thus, a discrepancy exists, but there is no identifiable means of identifying why the discrepancy exists.

The results also highlighted that three were a significant number of additional investigations on the west coast. Oregon, California, and Washington together total less than $15 \%$ of all the health clubs in the United States, but they represented $49 \%$ of all the OSHA fitness club investigations. The number of serious violations found in the analyzed cases was $29 \%$ while $65.9 \%$ of the cases had violations. Based on frequency of state investigations, some OSHA investigators gave priority to investigating serious violations, 
which would be consistent with OSHA's new Field Operations Manual's directive to emphasize serious concerns prior to regular violations. This perspective was also seen in the greater number of safety inspection for private clubs $(57 \%)$ compared with only $43 \%$ of the investigations focusing on health concerns. The disparity between private fitness facilities and YMCA was also seen in the number of health based inspections (70\%) which carry lower penalties compared with only $43 \%$ of the private clubs having health based investigations. There is no known reason for this significant disparity. However, $70 \%$ of all private investigations were based on complaints compared to $61 \%$ for YMCAs. This would tend to show that all fitness facilities need to provide a safe workplace to prevent complaints. However, once complaints are filed there seems to be a disparity as to the number of and types of violations investigated by OSHA.

Based on the significant potential penalties and the number of complaint inspired investigations, fitness facility owners and managers need to understand what OSHA requires and to carefully follow those mandates. The need to know and follow the law is even more acute on the west coast and for those who own/manage private fitness facilities.

\section{CONCLUSION}

OSHA regulations require significant attention to detail as the potential for non-compliance could result in significant time and financial commitment. This is in addition to having a workplace where employees can face harm from numerous hazards. Since so many OSHA regulations involve developing and implementing policies and procedures to insure a safe workplace, the compliance cost is not that significant and the risk of non-compliance could be very significant.

While the data shows that there could be a disparity between private and non-profit fitness facilities, similar differences could possibly be seen in other industry segments based on the investigators, the region, accident trends, and a host of other potential concerns that might not ever impact the decision to investigate a given employer. If a tragedy occurs at a fitness facility, the club management team must be able to meet with OSHA or other agencies, guide the inspection process, oversee responding to requests for documentation, facility tours, or even interviewing employees (Pasek, 2002). Thus, management needs to appreciate the implications associated with noncompliance and the resulting business interruption and possible damages that could occur if an employee is injured. 
Managers should not consider OSHA an enemy. Instead, OSHA can act as a guide to help provide a safer workplace and a safer workplace will result in happier employees along with a better work environment. The ultimate win-win scenario is a safe fitness facility for all.

\section{ABOUT THE AUTHOR}

GIL FRIED is a Professor at the University of New Haven and Chair of the Sport/Hospitality and Tourism Management Department. He specializes in sport risk management, finance, and facility management.

\section{REFERENCES}

American College of Sport Medicine (ACSM). (2007). Health/Fitness facility standards and guidelines (3rd Ed.). Champaign, IL: Human Kinetics.

Barnett, J. S. (2001). Responding to OSHA investigations and citations. ConnellFoley. Retrieved January 3, 2007, from http://www.cfglawfirm.com/seminar/employosha.html

Bloodborne pathogens 29 C.F.R. 1910.1030 (2009).

Broadhag, K. (2005, December). Facility maintenance and OSHA compliance. Fitness Management. OSHA. (2003). Personal protective equipment. Washington, D.C.: U.S. Department of Labor, OSHA publication 3151-12R. Retrieved April 1, 2009 from http://www.osha.gov/Publications/ osha3151.pdf

Brodsky, D. (2002). Health club hearing hazard. Gym America Magazine.

Bureau of Labor Statistics (2006, October 19). Workplace injuries and illnesses in 2005. OS NR 10/19/2006 News Release. Retrieved January 3, 2007, from http://www.bls.gov/iif/oshwc/osh/os/osnr0025.txt

Connaughton, D., Demichele, D., Horodyski, M., \& Dannecker, E. (2002, Spring/Summer). An analysis of OSHA compliance and selected risk management practices of NIRSA fitness directors. Recreational Sports Journal, 26(1), 7-17.

Coy, P. (2007, November 12). It's safer than ever to go to work. BTW. Business Week, 23.

Fatal occupational injuries. (2003, April). Compliance Magazine, 11(4), 4.

Fried, G., \& Miller, L. (1998) Employment law. Durham, North Carolina: Carolina Academic Press.

General safety and health provisions, 29 C.F.R. 1926.20 (2009). 
International Health, Racquet and Sportsclubs Association (IHRSA). (2003, July 16). IHRSA and OSHA Fast Fix team up to keep your club safe. Retrieved on April 1, 2009, from http://cms.ihrsa.org/index.cfm?fuseaction=Page. viewPage \&pageId $=15718 \&$ nodeID $=15$

International Health, Racquet and Sportsclubs Association (IHRSA). (2007). 2007, The IHRSA profiles of success: The annual industry data survey of the health and fitness club industry. Boston, MA: International Health, Racquet and Sportsclubs Association.

International Health, Racquet and Sportsclubs Association (IHRSA) (2008). About the industry. (2008). Retrieved April 1, 2009, from http://cms.ihrsa.org/index.cfm?fuseaction=Page.viewPage\&pageId=18735\& nodeID $=15$

Kenworthy, W. (2002). OSHA training requirement. Trucking Trends.

Nash, J. (2005, February 25). Justice Dept. drops most criminal OSHA referrals. EHS Today. Retrieved July 18, 2008 from http://occupationalhazards.com/ Issue/Article/36865/Justice_Dept_Drops_Most_Criminal_OSHA_Referrals. aspx

Occupational noise exposure, 29 C.F.R. 1910.95 (2009).

OSHA. (1996). Federal employer rights and responsibilities following an OSHA inspection. Retrieved November 13, 2002, http://www.osha.gov/ Publications/fedrites.html

OSHA. (1997). Seek and ye shall not find. OSHA DATA. Retrieved April 1, 2009, from http://web.archive.org/web/20061205021405/http://oshadata. com/fssy.htm

OSHA. (2004, December). OSHA Facts - - December 2004. U.S. Department of Labor. Retrieved April 1, 2008, from http://www.safetyunited.com/en/rel/4/

OSHA. (2007, August). OSHA Facts-August 2007. Washington, D.C.: U.S. Department of Labor.

OSHA. (2009). Evacuation plans and procedures. Retrieved April 1, 2009, from http://www.osha.gov/SLTC/etools/evacuation/eap.html

Pasek, J. (2002, August). Crises management for HR. HR Magazine, 111-116.

Rogers, E., \& Wiatrowski, W. (2005, October). Injuries, illness, and fatalities among older workers. Monthly Labor Review, 24-30. Retrieved April 1, 2009 from www.bls.gov/opub/mlr/2005/10/art3full.pdf

Safety/OSHA Update. (2004). High Safety Consulting Services Newsletter. Lancaster, PA: High Safety Consulting Services, LTD. 
SIC Description for 7991 (2008). U.S. Department of Labor. Retrieved July 14, 2008, from http://www.osha.gov/pls/imis/sic_manual.display?id=183\&tab= description.

Sinclair, U. (1906). The jungle. New York, NY: Doubleday, Page \& Company.

UAW-Local 2209 Roanoke, IN (2008). Facts about worker health and safety. Retrieved April 1, 2008, from http:/www.local2209.org/committee/ healthsaftey/default7.asp.

U.S. Department of Labor. (1997). Assessing the need for personal protective equipment: A guide for small business employees. Washington, D.C.: Small Business Safety Management Series, OSHA publication 3151.

U.S. Department of Labor (2000). OSHA Facts. Washington, D.C.: U.S. Department of Labor.

U.S. Department of Labor (2002a). OSHA Facts. Washington, D.C.: U.S. Department of Labor.

U.S. Department of Labor (2002b). OSHA FACT sheet, job safety and health. Washington, DC: U.S. Department of Labor.

U.S. Department of Labor. (2003, September 16). Club Managers Association of America forms alliance with OSHA. U.S. Department of Labor, Press Release.

U.S. Department of Labor. (2005). Fatality/Catastrophe Investigation Procedures. OSHA Instruction, CPL 02-00-137. Retrieved April 30, 2009, from http://www.osha.gov/pls/oshaweb/owadisp.show_document?p_table=DIRE CTIVES\&p_id $=3245$

U.S. Department of Labor. (2008, April 3). Occupational employment and wages, May 2007. Retrieved March 23, 2009, from http://www.bls.gov/oes/ current/oes399031.htm

U.S. Department of Labor. (2009). Field Operations Manual. CPL 02-00-148. Retrieved April 30, 2009, from http://www.osha.gov/pls/oshaweb/owadisp. show_document?p_table=DIRECTIVES\&p_id $=4160$

W.G. Fairfield Company v. The Occupational Safety \& Health Review Commission, 285 F.3d 499 (6th Cir. 2002).

Walsh, E. (2001, April 9). Dancing till deaf. Hearing Rehabilitation Quarterly. Retrieved on April 1, 2009 from http:/www.lhh.org/noise/archives/ hrq_dancetilldeaf.html

Washington State Department of Labor and Industries. (2004). Claim Counts and Costs by Standard Occupational Class 2000 (SOC2K) Code Description and 
Risk Group. Planning and Research Services, State of Washington Department of Labor and Industries.

William-Steiger Occupational Safety and Health Act (OSHA) of 1970, 29 U.S.C. $\S 651$, et seq. (2008).

Worker death toll declines. (2007, October 29). Business New Haven, XV(2), 7.

YMCA. (2009). About the YMCA. Retrieved March 19, 2009, from http://www.ymca.net/about_the_ymca/ 